\title{
Annual alveolar bone loss in older adults taking oral bisphosphonate: a retrospective cohort study
}

\author{
Mohammad Helmi ${ }^{1}$, Sara AlOsaimy ${ }^{2,3}$, J. Max Goodson ${ }^{4}$, Hatice Hasturk ${ }^{5}$ and Zuhair S. Natto ${ }^{6 *}$ (D)
}

\begin{abstract}
Background: Although several studies assessed the effect of bisphosphonate (BIS) administration on alveolar bone loss, this relationship has not been fully investigated using longitudinal analysis. The aim of the this article is to predict annual alveolar bone loss in a subpopulation of older adults patients who were taking oral bisphosphonate (BIS), adjusting for systemic diseases and associated risk factors.

Methods: This is a retrospective cohort study. We identified all subjects who reported receiving oral bisphosphonate from 2008 to 2015 ( $N=30$ ) using the electronic health records of each patient to identify suitable radiographs for analysis. For the longitudinal data analysis, 26 subjects were eligible for inclusion, having at least two exposures of the complete mouth set or repeated bitewing radiographs at least a one-year interval; they were then matched on age and sex to another 26 patients who did not report receiving bisphosphonate at any point of their life.

Results: Mild periodontitis was higher in the BIS group compared to the no BIS group; however, moderate periodontitis was higher in the no BIS group. For those who did not take oral BIS, change over time was not significant after the twoyear period. However, the BIS group had experienced $0.088 \mathrm{~mm}$ more bone loss compared to the no BIS group (95\% Cl: $0.001,0.176$. $P$-value $=0.048$, adjusting for all other variables included in the model.

Conclusion: The group that reported receiving oral bisphosphonates showed no improvement in maintaining alveolar bone level, and the use of oral BIS may not be effective in reducing annual alveolar bone loss; however, emerging evidence is promising for the use of bisphosphonate as an adjunctive local delivery medication for the management of periodontal diseases.
\end{abstract}

Keywords: Bisphosphonate, Periodontal disease, Annual bone loss, Predict

\section{Background}

Although several studies raised the question of whether increased alveolar bone loss is a natural consequence of aging [1-5], a higher prevalence of periodontitis and bone loss in general have been consistently addressed and reported in the literature to be associated with aging [4-9].

Periodontitis was also reported in the literature to be associated with age-related diseases, such as osteoporosis, especially in postmenopausal women [10-13]. In 2018, Mashalkar et al. published a study on postmenopausal women to investigate the correlation between periodontitis

\footnotetext{
* Correspondence: znatto@kau.edu.sa

${ }^{6}$ Department of Dental Public Health, School of Dentistry, King Abdulaziz

University, Jeddah, Saudi Arabia

Full list of author information is available at the end of the article
}

and osteoporosis [14]. Authors of the study concluded that there was significant association between osteoporosis in postmenopausal women and the severity of periodontitis.

Multiple studies also assessed the effect of bisphosphonate (BIS) administration on alveolar bone loss [15-17]. Bisphosphonates were introduced to clinical practice decades ago $[18,19]$. They are structurally related to inorganic pyrophosphate, as they contain a core phosphate-carbon-phosphate structure with the highest affinity for the bone relative to other tissues. Bisphosphonates inhibit enzymatic degradation, hinder calcification and suppress bone resorption. They are utilized in conditions where there is an imbalance between osteoblastmediated bone formation and osteoclast bone resorption. 
Bisphosphonates are the mainstay of therapy for skeletal disorders, particularly osteoporosis due to skeletal remodeling, because they achieve a high concentration to active bone remodeling sites, with conditions such as those with accelerated skeletal turnover [18-20]. They increase the density of the bone, reduce markers of bone turnover and ultimately reduce fractures [19]. In addition, bisphosphonates are utilized to resolve hypercalcemia among cancer patients [18-20]. Other clinical implications include: primary hyperparathyroidism, osteogenesis imperfecta and paget's disease of bone [20]. However, it may lead to bisphosphonate-related osteonecrosis of the jaw (BRONJ), which was renamed to medication-related osteonecrosis of the jaw (MRONJ). This is related other bone resorption inhibitors or angiogenesis inhibitors, due to the excessive inhibition of angiogenesis and jaw metabolic processes, toxicity, inflammation, immunity disorder and infection [21, 22].

Due to its marked efficacy in the prevention of bone loss in susceptible populations, alendronate (generic name of BIS) had been proposed as a useful agent to prevent alveolar bone loss [22]. One systematic review assessed eight clinical studies that evaluated the efficacy of bisphosphonate therapy in the management of periodontitis, particularly as an adjunct to scaling and root planing [23]. Alendronate was utilized as either a topical application or oral therapy option. The study concluded that there was a statistically significant reduction in probing depth and bone defect, suggesting the clinical effectiveness of bisphosphonate in the management of periodontitis.

Another group investigated the potential outcomes of alendronate among postmenopausal women with periodontal disease [24]. Postmenopausal women are at the highest risk for osteoporosis due to estrogen deficiency. Authors of the study concluded that oral alendronate improved periodontal health and alveolar bone turnover in postmenopausal women.

Moreover, El-Shinnawi et al. in 2003 published a clinical trial on 24 adults with periodontitis that had been followed for 6 months [25]. Twelve patients were administered oral alendronate and were compared to a control group that did not receive any drug. Although clinical parameters (attachment level, pocket depth and gingival index) of the alendronate group showed no difference compared to the control group, the alendronate group showed a significant change in bone density compared to the control group, favoring patients who received oral bisphosphonate. For this reason, the aim of this study is to evaluate annual alveolar bone loss in a subpopulation of older adults patients who were taking oral bisphosphonate, adjusting for systemic diseases and associated risk factors. We hypothesized that BIS patients would have less alveolar bone loss compared with no BIS.

\section{Methods}

This is a retrospective cohort study that followed STROBE checklist. It was approved by the office of human research administration, Harvard Faculty of Medicine, [45 CFR 46.101(b) (4)], \#IRB 16-1838. We collected records of all patients that reported receiving oral BIS from 2008 to $2015(N=30)$, to identify suitable radiographs for analysis. To be included in the study, each patient should have at least two exposures of Complete Mouth Radiographic Series (CMRS) or repeated bitewing (BW) radiographs at least a one-year interval. Furthermore, each BW radiograph had to clearly show the alveolar bone crest and cement-enamel junction, as well as show at least two posterior approximating teeth to be included. Exclusion criteria used were: 1$)$ patients that were not within the specified age range, 2) patients with no BW radiographs, 3) patients with radiographs in which the cement-enamel junction (CEJ) and alveolar bone crest were not visible, 4) patients who did not have at least 2 approximating teeth or where the interproximal space was too narrow to observe the bone crest. Teeth were excluded if dental restorations obliterated the CEJ, rendering the distance between CEJ and alveolar crest questionable. Additionally, cases in which a tooth was found adjacent to an edentulous site with alveolar bone levels greater than 2 $\mathrm{mm}$ from the CEJ were not considered pathological due to possible surgical trauma. Any records indicating sites receiving osseous surgery or bone grafts were excluded. Patients were excluded as well due to closed electronic files or because their BW radiographs could not be calibrated with the measuring tool. Third molar teeth were not included due to their tendency of not being captured by BW radiographs. Non-functional teeth were excluded for the possibility of super eruption. For longitudinal data analysis, we required that eligible subjects for inclusion to have at least two exposures of complete mouth survey radiographs or repeated BW radiographs with at least one-year interval.

\section{Primary predictor}

The main predictor was whether or not the subjects had reported taking oral BIS. Other variables included in the model were age, sex (although we did not expect any confounding by age or sex, since the two groups were matched on them, we included them to account for any residual confounding), smoking status, median house income, race, diabetes and hypertension. All data were collected from the electronic health record of the Harvard Dental Center using AxiUm ${ }^{\circ}$ software. Due to the small number of this sample, categorization to different age categories resulted in groups with very few subjects (presented in the descriptive statistics section). Hence, age was used as a continuous predictor for the multivariable 
analysis. Furthermore, we categorized body mass index (BMI) into two groups of Underweight/Normal weight and Overweight/Obese, with the former group as the reference group for the same reason of scarce data.

In this sample, no one had reported as being current smoker so we created a binary smoking variable for analysis by coding everyone who had ever smoked (former smoker) as ever smoker $(=1)$ and those who had never smoked as never smoker $(=0)$.

\section{Primary outcome}

The primary outcome is the mean of the alveolar bone level on mesial and distal sites of posterior teeth in millimeters between the group that was taking oral BIS and the group that was not. The bone levels at the follow-up visits were compared to the baseline mean of both groups. Interproximal bone loss occurs when the distance between the cement-enamel junction (CEJ) and the alveolar bone crest is greater than or equal to $2 \mathrm{~mm}$, as determined on a bitewing radiograph [26-31]. We also classified the amount of bone loss based on the American Academy of Periodontology (AAP) case definition into mild, moderate and severe periodontitis to estimate the prevalence [26]. One trained examiner $(\mathrm{MH})$ carried out the measurement of the outcome using the calibrated measuring tool of Emago ${ }^{\circ}$ after conducting the inter-examiner reliability test. An intra class correlation coefficient (ICC) test was performed with an excellent average score of 0.96 (0.93-0.97).

\section{Sample size}

This is a subpopulation of a large sample size $(N=1131)$ collected to estimate prevalence of periodontal diseases in HSDM. After identifying patients who reported using bisphosphonates, we implemented very strict exclusion criteria (described before). We further selected patients on the availability of repeated radiographs that affected the total number of eligible patients. We collected records of all patients that reported receiving oral BIS from 2008 to $2015(N=30)$, to identify suitable radiographs for analysis. We identified 26 patients out of the 30 identified earlier that satisfied inclusion criteria described before. The 26 patients who were taking BIS were then matched on age and sex to another 26 patients who did not report receiving BIS at any point of their life. Radiographs of a total of 52 patients $(26$ patients of each group) were analyzed over a two-year period.

It is true sample size is quite small due to the low number of patients reported taking BIS. To address this problem we calculated the power of detecting at least $0.5 \mathrm{~mm}$ difference between the two groups. The main sample of this subpopulation had an average mean alveolar bone level of $1.38 \mathrm{~mm}( \pm 0.7)$. Given these parameters, with $\alpha$ set to 0.05 , we have more than $80 \%$ power to detect a real difference. This could also mean that the two groups might differ in less than $0.5 \mathrm{~mm}$ of mean alveolar bone level. However such a difference might be considered clinically insignificant.

\section{Statistical analyses}

Descriptive statistics of categorical data as well as the prevalence of each periodontitis case definition were calculated. A mixed-effect linear regression model with a multi-level design was performed to estimate the difference of change in mean bone level in millimeters $(\mathrm{mm})$. We included the time term to adjust for the amount of change across the years of follow up for both groups.

\section{Results}

\section{Descriptive statistics (univariate analysis)}

A total of 52 matched subjects were included in the final analysis. Median age of participants was 70 year-old (IQR: 64-78) (Table 1). African American race was the fewest in this sample, composing almost $2 \%$, while $54 \%$ of the sample was White. Table 2 presents different racial groups and other predictors with their measured mean bone levels. The BIS group mean alveolar bone level at baseline was $1.90 \mathrm{~mm}( \pm 0.040)$ and $1.99 \mathrm{~mm}$ $( \pm 0.036)$ for the group that is not taking BIS. Of the subjects, $21 \%$ were former smokers and none of the subjects have reported themselves as current smokers.

\section{Severity of the disease based on case definitions}

The overall prevalence of mild periodontitis was $94.2 \%$ $( \pm 3.2)$, moderate periodontitis was $50 \%( \pm 7.0)$ and severe periodontitis was $7.7 \%( \pm 3.7)$ (Table 2$)$. Mild periodontitis was higher in the BIS group compared to the no BIS group; however, moderate periodontitis was higher in the no BIS group (Table 1). Moreover, moderate and severe periodontitis were higher among individuals with low median house income (Fig. 1).

Table 1 Prevalence of mild, moderate, and severe periodontitis comparing both groups of patients at baseline

\begin{tabular}{clllllll}
\hline & $N$ & Median Age & IQR & Females \% & Mild \% & Moderate \% & Severe \% \\
\hline Total & 52 & 70 & $64-78$ & 92.3 & 94.2 & 50.0 & \\
BIS & & & & & & \\
Yes & 26 & 70 & $64-78$ & 92.3 & 96.1 & 38.4 & 7.7 \\
No & 26 & 70 & $64-78$ & 92.3 & 92.3 & 61.5 & 7.7 \\
\hline
\end{tabular}


Table 2 Descriptive statistics and prevalence of mild, moderate, and severe periodontitis of the whole sample at baseline

\begin{tabular}{|c|c|c|c|c|c|c|c|c|c|}
\hline \multicolumn{10}{|l|}{ Percentage (\%) } \\
\hline & $N$ & Mild & SE & Moderate & SE & Severe & SE & MABL $(\mathrm{mm})^{\mathrm{a}}$ & SE \\
\hline Total & $52(100)$ & 94.2 & 3.2 & 50.0 & 7.0 & 7.7 & 3.7 & 1.94 & 0.027 \\
\hline \multicolumn{10}{|l|}{ Age Groups (yrs.) } \\
\hline $50-64$ & $14(26.9)$ & 100.0 & 0.0 & 50.0 & 13.8 & 7.1 & 7.1 & 2.02 & 0.050 \\
\hline $65+$ & $38(73.1)$ & 92.1 & 4.4 & 50.0 & 8.2 & 7.9 & 4.4 & 1.91 & 0.032 \\
\hline \multicolumn{10}{|l|}{ Gender } \\
\hline Male & $4(7.7)$ & 100.0 & 0.0 & 25.0 & 25.0 & 0.0 & $\mathrm{n} / \mathrm{a}$ & 1.76 & 0.067 \\
\hline Female & $48(92.3)$ & 93.7 & 3.5 & 52.1 & 7.2 & 8.3 & 4.0 & 1.96 & 0.029 \\
\hline \multicolumn{10}{|l|}{ Race } \\
\hline White & $28(53.9)$ & 96.4 & 3.5 & 53.5 & 9.6 & 7.1 & 4.9 & 1.98 & 0.035 \\
\hline African American & $1(1.9)$ & 100.0 & 0.0 & 100.0 & 0.0 & 0.0 & $\mathrm{n} / \mathrm{a}$ & 2.45 & 0.232 \\
\hline Asian & $6(11.5)$ & 100.0 & 0.0 & 83.3 & 16.6 & 33.4 & 21.1 & 2.19 & 0.106 \\
\hline Other & $4(7.7)$ & 100.0 & 0.0 & 25.0 & 25.0 & 0.0 & $\mathrm{n} / \mathrm{a}$ & 1.50 & 0.074 \\
\hline Unknown & $13(25)$ & 88.9 & 11.1 & 33.4 & 16.7 & 0.0 & $\mathrm{n} / \mathrm{a}$ & 1.83 & 0.047 \\
\hline \multicolumn{10}{|c|}{ Median House Income } \\
\hline Low & $16(30.7)$ & 87.5 & 8.5 & 68.7 & 11.9 & 12.5 & 8.5 & 2.08 & 0.051 \\
\hline High & $36(69.3)$ & 97.2 & 2.7 & 41.7 & 8.3 & 5.5 & 3.8 & 1.88 & 0.031 \\
\hline \multicolumn{10}{|l|}{ Body Mass Index } \\
\hline Underweight & $2(3.8)$ & 100.0 & 0.0 & 100.0 & 0.0 & 0.0 & $\mathrm{n} / \mathrm{a}$ & 2.29 & 0.119 \\
\hline Normal & $18(34.6)$ & 100.0 & 0.0 & 50.0 & 12.1 & 5.6 & 5.6 & 1.91 & 0.043 \\
\hline Overweight & $10(19.2)$ & 80.0 & 13.3 & 30.0 & 15.2 & 10.0 & 10.0 & 1.68 & 0.064 \\
\hline Obese & $4(7.7)$ & 75.0 & 25.0 & 25.0 & 25.0 & 0.0 & $\mathrm{n} / \mathrm{a}$ & 1.57 & 0.070 \\
\hline Not reported & 18 (34.6) & 100.0 & 0.0 & 61.1 & 11.8 & 11.1 & 7.6 & 2.16 & 0.048 \\
\hline \multicolumn{10}{|l|}{ Smoking Status } \\
\hline Never smoker & $13(25)$ & 84.6 & 10.4 & 46.1 & 14.4 & 7.7 & 7.7 & 1.73 & 0.047 \\
\hline Former smoker & $11(21.1)$ & 100.0 & 0.0 & 45.5 & 15.7 & 18.2 & 12.2 & 2.05 & 0.064 \\
\hline Current Smoker & 0 & 0.0 & $\mathrm{n} / \mathrm{a}$ & 0.0 & n/a & 0.0 & $\mathrm{n} / \mathrm{a}$ & 0.0 & $\mathrm{n} / \mathrm{a}$ \\
\hline Not reported & $28(53.9)$ & 96.4 & 3.5 & 53.5 & 9.6 & 3.5 & 3.5 & 2.0 & 0.037 \\
\hline \multicolumn{10}{|c|}{ Bisphosphonate intake } \\
\hline Yes & $26(50)$ & 96.1 & 3.8 & 38.4 & 9.7 & 7.7 & 5.3 & 1.90 & 0.040 \\
\hline No & $26(50)$ & 92.3 & 5.3 & 61.5 & 9.7 & 7.7 & 5.3 & 1.99 & 0.036 \\
\hline \multicolumn{10}{|l|}{ Diabetes } \\
\hline Yes & $2(3.9)$ & 100.0 & 0.0 & 0.0 & $\mathrm{n} / \mathrm{a}$ & 0.0 & $\mathrm{n} / \mathrm{a}$ & 1.54 & 0.102 \\
\hline No & $50(96.1)$ & 94.0 & 3.4 & 52.0 & 7.1 & 8.0 & 3.8 & 1.95 & 0.027 \\
\hline \multicolumn{10}{|l|}{ CVD } \\
\hline Yes & $15(28.9)$ & 93.4 & 6.6 & 40.0 & 13.1 & 6.7 & 6.7 & 1.91 & 0.048 \\
\hline No & $37(71.1)$ & 94.6 & 3.7 & 54.0 & 8.3 & 8.1 & 4.5 & 1.95 & 0.032 \\
\hline \multicolumn{10}{|l|}{ Hypertension } \\
\hline Yes & 35 (67.3) & 94.1 & 5.8 & 35.3 & 11.9 & 11.7 & 8.0 & 1.85 & 0.047 \\
\hline No & 17 (32.7) & 94.2 & 3.9 & 57.1 & 8.4 & 5.7 & 3.9 & 1.98 & 0.033 \\
\hline
\end{tabular}

${ }^{\mathrm{a}}$ Mean alveolar bone level in millimeters

Unadjusted estimates overtime (bivariate analysis)

After the two-year interval, the group with no history of receiving oral BIS did not experience significant change in mean bone level. On the other hand, the BIS group had experienced $0.087 \mathrm{~mm}$ mean bone loss after 2 years with marginally statistical significance compared to the 


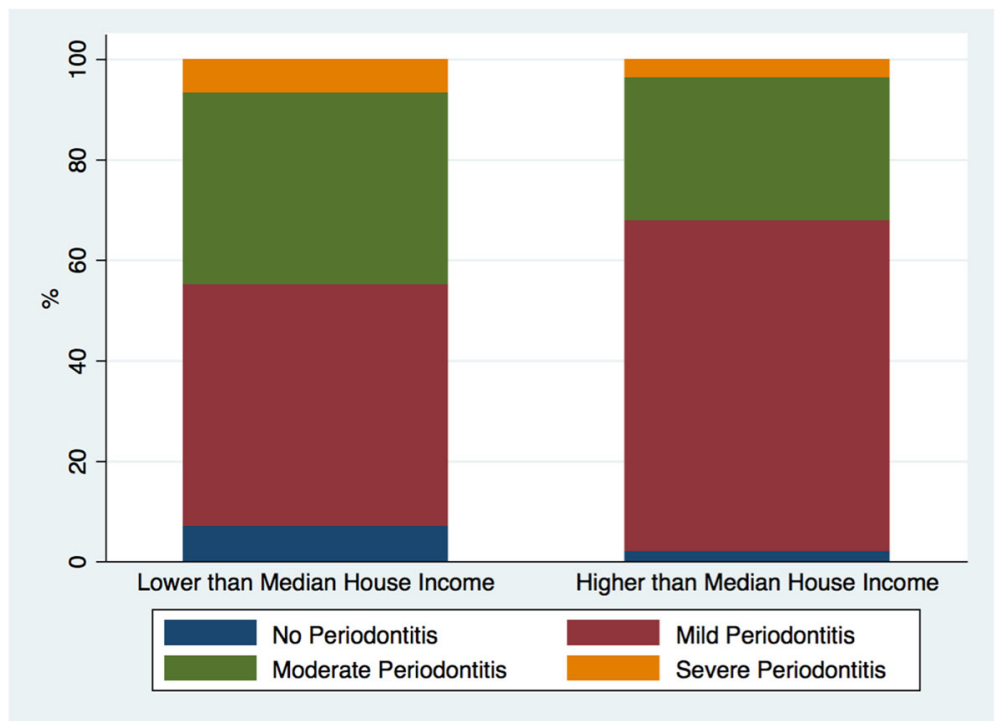

Fig. 1 Prevalence of mild, moderate, and severe periodontitis by median house income

group with the no BIS intake baseline (95\% CI: -0.0002 , 0.175 . $P$-value $=0.051$ ). Table 3 presents the bivariate analysis and its unadjusted estimates of mean bone loss at baseline and over time.

\section{Adjusted estimates over time (multi-variable analysis)}

Since subjects were matched on age and sex, we did not expect adding these two variables to the model would affect the outcome significantly. However, we included them to control for any residual confounding by age or sex. None of the variables included in the model showed significant association with the outcome. For the group who did not take oral BIS, change over time was not significant after the two-year period. However, the BIS group had experienced $0.088 \mathrm{~mm}$ more bone loss compared to the no BIS group (95\% CI: $0.001,0.176 . P$-value $=0.048$ ), adjusting for all other variables included in the model. Table 3 presents the estimates at baseline and over time, in addition to the estimates of all other variables. A possible explanation of this observation is that the no BIS group received double the number of periodontal treatments (scaling and root planing) in the measured teeth after the first included $\mathrm{x}$-ray, compared to the BIS group, using Current Dental Terminology (CDT) codes from American Dental Association (Table 4).

\section{Random-effect estimates}

The estimates (mean change) of random effect vary between individuals and teeth. It was $0.14 \mathrm{~mm}$ (95\% CI: 0.10 , 0.17 ) and $0.12 \mathrm{~mm}$ (95\% CI: $0.10,0.13)$, respectively. Random-effect coefficients are also provided in Table 3.

\section{Discussion}

Results of this study indicate that, after 2 years of follow up, the oral administration of BIS did not have a protective effect on the mean alveolar bone loss. Although a recent systematic review and meta-analysis on the effect of BIS used as an adjunctive treatment of periodontal diseases indicated the beneficial effect of BIS administration, the authors concluded that due to short periods of follow up in the eight studies identified in the literature, as well as the potential adverse effect of BIS in the oral cavityosteonecrosis of the jaws, its use as an adjunctive treatment for managing periodontal diseases is debatable [23].

Another study, that was not included in the previously mentioned systematic review, was published by Jeffcoat et al. in 2007 to investigate the effectiveness of oral alendronate [17]. In that study, 335 patients were randomized into two groups of alendronate and no-drug groups and were followed over 24 months. After 2 years of follow up, the group receiving oral alendronate did not show any significant change in either alveolar bone density or alveolar bone loss compared to the control group.

Only patients that were having low mandibular bone mineral density at baseline showed significant reduction of bone loss compared to the control group. The authors of the study concluded that administering oral alendronate over 2 years for patients with periodontitis had no effect on alveolar bone loss except for the subpopulation of patients who had low mandibular bone mineral density.

Although studies that examined the effect of oral BIS disagreed on its effect on periodontal health [16, 17, 22, 24], the route of administration may play an integral role in the effectiveness of bisphosphonate on alveolar bone loss. 
Table 3 Crude and adjusted mean alveolar bone loss $(\mathrm{mm})$ for both groups over time

\begin{tabular}{|c|c|c|c|c|}
\hline Variables & $\begin{array}{l}\text { Adjusted MABL }(\mathrm{mm})^{\mathrm{a}} \\
95 \% \mathrm{Cl}\end{array}$ & $p$-value & $\begin{array}{l}\text { Unadjusted MABL }(\mathrm{mm})^{\mathrm{a}} \\
95 \% \mathrm{Cl}\end{array}$ & $p$-value \\
\hline \multicolumn{5}{|l|}{ Year ${ }^{\mathrm{a} B I S}$} \\
\hline \multicolumn{5}{|l|}{0 No BIS (reference) } \\
\hline 2 No BIS & $-0.027(-0.08,0.03)$ & 0.374 & $-0.027(-0.08,0.03)$ & 0.383 \\
\hline $0 \mathrm{BIS}+$ & $0.084(-0.16,0.033)$ & 0.515 & $-0.059(-0.27,0.15)$ & 0.594 \\
\hline 2 BIS+ & $0.088(0.001,0.176)$ & 0.048 & $0.087(-0.0002,0.175)$ & 0.051 \\
\hline \multicolumn{5}{|l|}{ Age (continious yrs) } \\
\hline 1 year increase & $-0.002(-0.016,0.012)$ & 0.764 & & \\
\hline \multicolumn{5}{|l|}{ Gender } \\
\hline \multicolumn{5}{|l|}{ Female (reference) } \\
\hline Male & $-0.312(-0.830,0.204)$ & 0.236 & & \\
\hline \multicolumn{5}{|l|}{ Race } \\
\hline \multicolumn{5}{|l|}{ White (reference) } \\
\hline African American & $0.476(-0.244,1.198)$ & 0.195 & & \\
\hline Asian & $0.092(-0.246,0.432)$ & 0.591 & & \\
\hline Other & $-0.289(-0.708,0.129)$ & 0.176 & & \\
\hline Unknown & $-0.108(-0.348,0.130)$ & 0.373 & & \\
\hline \multicolumn{5}{|l|}{ Median House Income ${ }^{a}$} \\
\hline \multicolumn{5}{|l|}{ Low (reference) } \\
\hline High & $-0.153(-0.405,0.098)$ & 0.233 & & \\
\hline \multicolumn{5}{|l|}{ Body Mass Index } \\
\hline \multicolumn{5}{|c|}{ Underweight/Normal (reference) } \\
\hline Overweight/Obese & $-0.235(-0.476,0.004)$ & 0.055 & & \\
\hline \multicolumn{5}{|l|}{ Smoking Status } \\
\hline \multicolumn{5}{|c|}{ Never smoker (reference) } \\
\hline Former smoker & $0.153(-0.199,0.505)$ & 0.394 & & \\
\hline Current Smoker & $\mathrm{n} / \mathrm{a}$ & $\mathrm{n} / \mathrm{a}$ & & \\
\hline \multicolumn{5}{|l|}{ CVD } \\
\hline \multicolumn{5}{|l|}{ No (reference) } \\
\hline Yes & $0.133(-0.165,0.433)$ & 0.381 & & \\
\hline \multicolumn{5}{|l|}{ Hypertension } \\
\hline \multicolumn{5}{|l|}{ No (reference) } \\
\hline Yes & $-0.118(-0.388,0.150)$ & 0.388 & & \\
\hline \multicolumn{5}{|l|}{ D4341 } \\
\hline \multicolumn{5}{|l|}{ No (reference) } \\
\hline Yes & $0.113(-0.169,0.396)$ & 0.433 & & \\
\hline \multicolumn{5}{|l|}{ Random effect } \\
\hline Between Individuals & $0.14(0.10,0.17)$ & $\mathrm{n} / \mathrm{a}$ & & \\
\hline Between Teeth & $0.12(0.10,0.13)$ & $\mathrm{n} / \mathrm{a}$ & & \\
\hline Between Sites & $0.21(0.19,0.22)$ & $\mathrm{n} / \mathrm{a}$ & & \\
\hline
\end{tabular}

$N=52$ patients (2307 sites from 658 teeth)

${ }^{a}$ Mean alveolar bone loss in millimeter 
Table 4 Proportion of patients received periodontal procedures including scaling and root planing comparing BIS and no BIS groups

\begin{tabular}{clll}
\hline & & $\mathrm{N}()$ & $\mathrm{N}(\%)$ \\
CDT Code & & $\mathrm{BIS}=1$ & $\mathrm{BIS}=0$ \\
\hline D4261 & Osseous surgery for one to three teeth & $2(7.7)$ & $0(0)$ \\
D4263 & Bone replacement graft & $3(11.5)$ & $4(15.4)$ \\
D4265 & Biologic materials - tissue regeneration & $3(11.5)$ & $3(11.5)$ \\
D4266 & Guided tissue regeneration & $1(3.8)$ & $0(0)$ \\
D4341 & Scaling/root planing for 4 teeth or more & $2(7.7)$ & $6(23)$ \\
D4342 & Scaling/root planing for 1-3 teeth & $6(23)$ & $10(38.4)$ \\
None & & $9(34.6)$ & $3(11.5)$ \\
Total & $26(100)$ & $26(100)$ \\
\hline CDT Current Dental Terminology & & \\
$N=52$ patients & &
\end{tabular}

The local delivery of $1 \%$ alendronate gel was also examined in patients with aggressive periodontitis (a more severe form of periodontal disease [32], and diabetic patients with chronic periodontitis (a systemic disease that is associated with a higher risk of developing periodontal diseases [33], as an adjunct to scaling and root planing for the treatment of intrabony defects. The researchers of both studies found a significant reduction in probing depth, greater gain of clinical attachment level, and bone reforming of intrabony defects. Moreover, an animal study conducted by Price et al., found that the local delivery of a simvastatin-alendronate- $\beta$-cyclodextrin was statistically associated with reduced bone loss as a consequence of periodontitis [34].

A partial-mouth periodontal examination would result in underestimating the true change in mean bone loss. However, we did not have missing outcomes related to loss to follow up (lack of radiographs); all 52 patients were followed for 2 years. Nevertheless, the sample size was relatively small, having only 26 patients in each group which may not representative of the entire population. However, the results of this research did not contradict our current knowledge using longitudinal analysis. Moreover, the BIS group may have exhibited underlying factors that affected their bone biology and resulted in an increased risk of bone loss that was not observed on this small group of patients, such as purpose for receiving it (part of the treatment for osteoporosis, malignant condition or systemic steroids), duration of use and doses.

\section{Conclusion}

Bisphosphonate medications are indicated for several bone-related diseases. In our study, we found that the group who reported receiving oral bisphosphonates showed no improvement in maintaining alveolar bone level-on the contrary, our results suggest that the use of oral BIS may not be effective in reducing annual alveolar bone loss. However, further investigation may be needed to investigate its role as an adjunct in periodontal therapy and the effect of treatment modalities on bone response. The implication of this study, however, may indicate that the route of administration of bisphosphonate plays an important role for its effectiveness to be achieved. Emerging evidence of several studies indicates that the local delivery of bisphosphonate can help in maintaining periodontal health and alveolar bone level for patients who are more prone to the periodontitis.

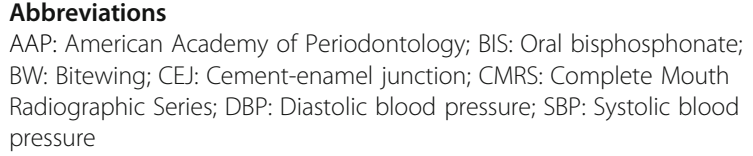
BW: Bitewing; CEJ: Cement-enamel junction; CMRS: Complete Mouth Radiographic Series; DBP: Diastolic blood pressure; SBP: Systolic blood pressure

\section{Acknowledgements}

This project was funded by the Deanship of Scientific Research (DSR), King Abdulaziz University, Jeddah, under grant no. (DF-053-165-1441). The authors, therefore, gratefully acknowledge DSR technical and financial support.

\section{Authors' contributions}

$\mathrm{MH}$ contributed to the study design, data collection, analysis and manuscript writing. ZN contributed to the study design, analysis (tables and analysis), interpretation and manuscript writing. SA, contributed to the study design, interpretation and manuscript writing. MG and $\mathrm{HH}$ contributed to the study design, interpretation and manuscript editing. All authors read and approved the final manuscript.

\section{Funding}

This project was funded by the Deanship of Scientific Research (DSR), King Abdulaziz University, Jeddah, under grant no. (DF-053-165-1441).

Availability of data and materials

The dataset used during the study are available from the corresponding author upon request.

\section{Ethics approval and consent to participate}

This study was approved by the office of human research administration, Harvard Faculty of Medicine, [45 CFR 46.101(b) (4)], \#IRB 16-1838, to use a secondary data from dental records. As the data was fully anonymous, and did not involve any experiments, no consent to participate or further administrative permissions /licenses were required or necessary.

\section{Consent for publication}

Not applicable.

\section{Competing interests}

The authors declare that they have no competing interests.

$$
\begin{aligned}
& \text { Author details } \\
& { }^{1} \text { Periodontics and Community Dentistry Department, College of Dentistry, } \\
& \text { King Saud University, Riyadh, Saudi Arabia. }{ }^{2} \text { Eugene Applebaum College of } \\
& \text { Pharmacy and Health Sciences, Detroit, Michigan, USA. }{ }^{3} \text { College of Pharmacy, } \\
& \text { King Saud University, Riyadh, Saudi Arabia. }{ }^{4} \text { Department of Oral Medicine, } \\
& \text { Infection, and Immunity, School of Dental Medicine, Harvard University, } \\
& \text { Boston, MA, USA. }{ }^{5} \text { Department of Applied Oral Sciences, Center for Clinical } \\
& \text { and Translational Research, The Forsyth Institute, Cambridge, MA, USA. } \\
& { }^{6} \text { Department of Dental Public Health, School of Dentistry, King Abdulaziz } \\
& \text { University, Jeddah, Saudi Arabia. }
\end{aligned}
$$


Received: 3 July 2019 Accepted: 11 November 2019

Published online: 27 November 2019

\section{References}

1. Burt BA. Periodontitis and aging: reviewing recent evidence. J Am Dent Assoc. 1994;125(3):273-9 Epub 1994/03/01.

2. Papapanou PN, Lindhe J, Sterrett JD, Eneroth L. Considerations on the contribution of ageing to loss of periodontal tissue support. J Clin Periodontol. 1991;18(8):611-5 Epub 1991/09/01.

3. Ship JA, Beck JD. Ten-year longitudinal study of periodontal attachment loss in healthy adults. Oral Surg Oral Med Oral Pathol Oral Radiol Endod. 1996; 81(3):281-90 Epub 1996/03/01.

4. Natto ZS, Aladmawy M, Alasqah M, Papas A. Factors contributing to tooth loss among the elderly: a cross sectional study. Singap Dent J. 2014;35:1722 Epub 2014/12/17.

5. Natto ZS, Aladmawy M, Alasqah M, Papas A. Is there a relationship between periodontal disease and causes of death? A cross sectional study. Braz Dent J. 2015;26(1):33-8 Epub 2015/02/13

6. Natto ZS, Al-Zahrani MS. Periodontal bone loss and self-reported medical conditions in a dental school patient population. J Int Acad Periodontol. 2010;12(4):104-9 Epub 2010/12/07.

7. Bliuc D, Nguyen ND, Alarkawi D, Nguyen TV, Eisman JA, Center JR. Accelerated bone loss and increased post-fracture mortality in elderly women and men. Osteoporos Int. 2015:26(4):1331-9 Epub 2015/01/21.

8. Eke PI, Wei L, Borgnakke WS, Thornton-Evans G, Zhang X, Lu H, et al. Periodontitis prevalence in adults $>/=65$ years of age, in the USA Periodontol. 2016;72(1):76-95 Epub 2016/08/09.

9. Dye BA, Tan S, Smith V, Lewis BG, Barker LK, Thornton-Evans G, et al. Trends in oral health status: United States, 1988-1994 and 1999-2004. Vital Health Stat 11. 2007:(248):1-92 Epub 2007/07/19.

10. Bando K, Nitta H, Matsubara M, Ishikawa I. Bone mineral density in periodontally healthy and edentulous postmenopausal women. Ann Periodontol. 1998:3(1):322-6 Epub 1998/09/02.

11. Jeffcoat MK. Osteoporosis: a possible modifying factor in oral bone loss. Ann Periodontol. 1998:3(1):312-21 Epub 1998/09/02.

12. Natto $Z \mathrm{~S}$, Hameedaldain A. Methodological quality assessment of metaanalyses and systematic reviews of the relationship between periodontal and systemic diseases. J Evid Based Dent Pract. 2019;19(2):131-39. Epub 2019 Jan 2.

13. Wang CJ, McCauley LK. Osteoporosis and periodontitis. Curr Osteoporos Rep. 2016;14(6):284-91 Epub 2016/10/04.

14. Mashalkar VN, Suragimath G, Zope SA, Varma SA. A cross-sectional study to assess and correlate osteoporosis and periodontitis among postmenopausal women: a dual energy X-ray absorptiometry study. J Midlife Health. 2018; 9(1):2-7 Epub 2018/04/10.

15. Badran Z, Kraehenmann MA, Guicheux J, Soueidan A. Bisphosphonates in periodontal treatment: a review. Oral Health Prev Dent. 2009;7(1):3-12 Epub 2009/05/05.

16. Haimov-Kochman R, Kochman T, Stabholz A, Hochner-Celinkier D. Bisphosphonate and estrogen replacement therapy for postmenopausal periodontitis. Isr Med Assoc J. 2004;6(3):173-7 Epub 2004/04/02.

17. Jeffcoat MK, Cizza G, Shih WJ, Genco R, Lombardi A. Efficacy of bisphosphonates for the control of alveolar bone loss in periodontitis. J Int Acad Periodontol. 2007;9(3):70-6 Epub 2007/08/25

18. Drake MT, Clarke BL, Khosla S. Bisphosphonates: mechanism of action and role in clinical practice. Mayo Clin Proc. 2008;83(9):1032-45 Epub 2008/09/09.

19. Grey A, Reid IR. Differences between the bisphosphonates for the prevention and treatment of osteoporosis. Ther Clin Risk Manag. 2006;2(1): 77-86 Epub 2008/03/25.

20. Vasikaran SD. Bisphosphonates: an overview with special reference to alendronate. Ann Clin Biochem. 2001:38(Pt 6):608-23 Epub 2001/12/06.

21. Landesberg R, Woo V, Cremers S, Cozin M, Marolt D, Vunjak-Novakovic G, et al. Potential pathophysiological mechanisms in osteonecrosis of the jaw. Ann N Y Acad Sci. 2011:1218:62-79 Epub 2011/02/05.

22. Baron R, Ferrari S, Russell RG. Denosumab and bisphosphonates: different mechanisms of action and effects. Bone. 2011:48(4):677-92 Epub 2010/12/15.

23. Rocha M, Nava LE, Vazquez de la Torre C, Sanchez-Marin F, Garay-Sevilla ME, Malacara JM. Clinical and radiological improvement of periodontal disease in patients with type 2 diabetes mellitus treated with alendronate: a randomized, placebo-controlled trial. J Periodontol. 2001;72(2):204-9 Epub 2001/04/06
24. Akram Z, Abduljabbar T, Kellesarian SV, Abu Hassan MI, Javed F, Vohra F. Efficacy of bisphosphonate as an adjunct to nonsurgical periodontal therapy in the management of periodontal disease: a systematic review. $\mathrm{Br}$ J Clin Pharmacol. 2017:83(3):444-54 Epub 2016/10/09.

25. Rocha ML, Malacara JM, Sanchez-Marin FJ, Vazquez de la Torre CJ, Fajardo ME. Effect of alendronate on periodontal disease in postmenopausal women: a randomized placebo-controlled trial. J Periodontol. 2004;75(12): 1579-85 Epub 2005/03/01.

26. El-Shinnawi UM, El-Tantawy SI. The effect of alendronate sodium on alveolar bone loss in periodontitis (clinical trial). J Int Acad Periodontol. 2003:5(1):510 Epub 2003/04/02.

27. American Academy of periodontology task force report on the update to the 1999 classification of periodontal diseases and conditions. J Periodontol. 2015;86(7):835-8 Epub 2015/07/01.

28. Laurell L, Romao C, Hugoson A. Longitudinal study on the distribution of proximal sites showing significant bone loss. J Clin Periodontol. 2003;30(4): 346-52 Epub 2003/04/16.

29. Natto ZS, Abu Ahmad RH, Alsharif LT, Alrowithi HF, Alsini DA, Salih HA, et al. Chronic periodontitis case definitions and confounders in periodontal research: a systematic assessment. Biomed Res Int. 2018;2018:4578782 Epub 2019/01/10

30. Sadeghi R. Prevalence of aggressive periodontitis in 15-18 year old schoolchildren in Tehran. Iran Community Dent Health. 2010;27(1):57-9 Epub 2010/04/30.

31. Savage A, Eaton KA, Moles DR, Needleman I. A systematic review of definitions of periodontitis and methods that have been used to identify this disease. J Clin Periodontol. 2009;36(6):458-67 Epub 2009/06/11.

32. Natto ZS, Almeganni N, Alnakeeb E, Bukhari Z, Jan R, lacono VJ. PeriImplantitis and Peri-implant mucositis case definitions in dental research: a systematic assessment. J Oral Implantol. 2019;45(2):127-31 Epub 2018/12/18.

33. Sharma A, Pradeep AR. Clinical efficacy of $1 \%$ alendronate gel in adjunct to mechanotherapy in the treatment of aggressive periodontitis: a randomized controlled clinical trial. J Periodontol. 2012;83(1):19-26 Epub 2011/05/26.

34. Price U, Le HO, Powell SE, Schmid MJ, Marx DB, Zhang Y, et al. Effects of local simvastatin-alendronate conjugate in preventing periodontitis bone loss. J Periodontal Res. 2013;48(5):541-8 Epub 2013/01/03.

35. Pradeep AR, Sharma A, Rao NS, Bajaj P, Naik SB, Kumari M. Local drug delivery of alendronate gel for the treatment of patients with chronic periodontitis with diabetes mellitus: a double-masked controlled clinical trial. J Periodontol. 2012:83(10):1322-8 Epub 2012/01/24

\section{Publisher's Note}

Springer Nature remains neutral with regard to jurisdictional claims in published maps and institutional affiliations.
Ready to submit your research? Choose BMC and benefit from:

- fast, convenient online submission

- thorough peer review by experienced researchers in your field

- rapid publication on acceptance

- support for research data, including large and complex data types

- gold Open Access which fosters wider collaboration and increased citations

- maximum visibility for your research: over $100 \mathrm{M}$ website views per year

At BMC, research is always in progress.

Learn more biomedcentral.com/submissions 